\title{
Effect of Various Nutritional Supplements on Hyaluronic Acid Production
}

\section{RESEARCH ARTICLE}

\author{
VJ Aroskar, SD Kamat and DV Kamat* \\ Department of Microbiology, Mithibai College of Arts, Chauhan Institute of Science \& Amruthben Jivanlal College of Commerce and \\ Economics, Vile Parle (W), Mumbai 400 056, INDIA
}

\begin{abstract}
Effect of various nutritional supplementations on production of hyaluronic acid (HA) using Streptococcus equi subsp. zooepidemicus ATCC 39920 was evaluated at shake flask. Among the different carbon sources used, maltodextin showed $\mathrm{HA}$ of $0.9 \mathrm{~g} / \mathrm{L}$ followed by $0.7 \mathrm{~g} / \mathrm{L}$ for dextrose. L-arginine $\mathrm{HCl}$ at $2.0 \mathrm{~g} / \mathrm{L}$ increased the yield of $\mathrm{HA}$ from $0.7 \mathrm{~g} / \mathrm{L}$ to $0.85 \mathrm{~g} / \mathrm{L}$. $\mathrm{L}$-arginine and L-glutamine showed the yield of $\mathrm{HA}$ of $0.7 \mathrm{~g} / \mathrm{L}$ and $1.0 \mathrm{~g} / \mathrm{L}$, respectively at $2.0 \mathrm{~g} / \mathrm{L}$ concentration. L-glutamine $(2.0 \mathrm{~g} / \mathrm{L})$ and uridine $(0.75 \mathrm{~g} / \mathrm{L})$ showed $\mathrm{HA}$ yield of 0.8 and $1.045 \mathrm{~g} / \mathrm{L}$, respectively. Addition of sodium glucuronate at 0.25 $\mathrm{g} / \mathrm{L}$ concentration at $8 \mathrm{~h}$, the yield of HA was increased from $0.7 \mathrm{~g} / \mathrm{L}$ to $0.85 \mathrm{~g} / \mathrm{L}$. Pantothenic acid at concentration of 8.33 $\mathrm{mg} / \mathrm{L}$ supplemented to the $\mathrm{P} 10$ medium, yield of $0.87 \mathrm{~g} / \mathrm{L}$ of HA was obtained. Active dry yeast at $5.0 \mathrm{~g} / \mathrm{L}$ increased yield of $\mathrm{HA}$ from $0.7 \mathrm{~g} / \mathrm{L}$ to $0.85 \mathrm{~g} / \mathrm{L}$. Tween 80 at higher concentration reduced $\mathrm{HA}$ production. The addition of $\mathrm{MgSO}_{4} .7 \mathrm{H}_{2} \mathrm{O}$ at 1.0 $\mathrm{g} / \mathrm{L}$ improved the production of HA. Other metal ions like manganese, ferrous, copper, and zinc have no significant effect on HA production. Thus, it has been found that various nutritional supplements have effect on production of HA using $S$. equi subsp. zooepidemicus ATCC 39920
\end{abstract}

\section{Received on: 14 Mar. 2012}

Accepted on: 8 May 2012

Published on: 16 Jan. 2013

DOI: $10.5195 /$ iioablett.2012.18

Keywords: Streptococcus zooepidemicus; Hyaluronic acid;L-arginine HCl; L-glutamine; Sodium glucuronate;Shake flask fermentation

\section{INTRODUCTION}

Hyaluronic acid (HA) is a high molecular weight linear polysaccharide composed of repeating units of $D$ glucuronic acid and $\mathrm{N}$-acetylglucosamine linked by $\beta$ (1$3)$ and $\beta$ (1-4) glycosidic bonds. With its unique physiological and biological properties such as high water-holding capacity, viscoelasticity, and biocompability, HA has a wide range of applications in the fields of medicine and cosmetics, including osteoarithritis treatment, ophthalmic surgery, plastic surgery, drug delivery, skin moisturizers, and wound healing (Chong et al., 2005; Kogan et al., 2007).

HA is typically found in connective tissues of animals as well as in the capsules of Streptococci spp. Traditionally, HA has been extracted from rooster combs, however, microbial production is receiving increased attention for prevention of viral infection. Furthermore, microbial fermentation of polysaccharide offers additional advantages. The purification is relatively simple and avoids the use of hazardous solvents during purification processes (Chen et al., 2009). Currently, the commonly used strain for microbial HA production on an industrial scale is Streptococcus zooepidemicus, which synthesizes HA as the extracellular capsule (Duan et al., 2008). Much work such as improving the fermentation process (Duan et al., 2008; Liu et al., 2008b) adding lysozyme
(Ogradowski et al., 2005), the alkaline-strategy (Liu et al., 2008a), adding hydrogen peroxide and ascorbate (Liu et al., 2009) and changing the medium composition (Rangaswamy and Jain 2008; Zhang et al., 2006) has been done to increase the production yield of HA in Streptococcus species. Although many studies have been performed on HA production, but very few reports were published on study of different supplementation to increase the production of HA.

In this study, we have investigated effect of various nutritional factors like amino acids (L-arginine $\mathrm{HCl}$ and L-glutamine), nutritional supplements (uridine and sodium glucuronate) to produce higher amounts of HA in Streptococcus equi subsp. zooepidemicus ATCC 39920 at shake flask.

\section{MATERIALS AND METHODS}

\section{Bacterial Strain and Preservation}

Streptococcus equi subsp. zooepidemicus ATCC 39920 was obtained from American Type Culture Collection (ATCC) USA.The strain was maintained and preserved on brain heart infusion (BHI) agar slant and in glycerol stock at 4 and $-80{ }^{\circ} \mathrm{C}$, respectively.

\section{Cultivation}


The culture from ampoule was revived on brain heart infusion agar plate under incubation at $37 \pm 1^{\circ} \mathrm{C}$ for $24 \mathrm{~h}$. The single mucoid colony was inoculated in $100 \mathrm{ml}$ of P10 medium in $500 \mathrm{ml}$ Erlenmeyer flask up to pH 6.3-6.4, ( $\mathrm{A}_{600}$ 2.0) and sterilized glycerol was added to make glycerol stocks of $20 \% \mathrm{v} / \mathrm{v}$. The culture was maintained as slants, glycerol stock and in lyophilized form. The glycerol stocks were stored at $-80^{\circ} \mathrm{C}$ where as slant and lyophilized vials were stored at $4{ }^{\circ} \mathrm{C}$. Precultures were carried out in a $250 \mathrm{ml}$ Erlenmeyer flask with $50 \mathrm{ml}$ of the P10 medium which contained $10 \mathrm{~g} / \mathrm{L}$ peptone bacteriological, $5.0 \mathrm{~g} / \mathrm{L}$ yeast extract, $10.0 \mathrm{~g} / \mathrm{L} \mathrm{KH}_{2} \mathrm{PO}_{4}$, $5.0 \mathrm{~g} / \mathrm{L} \mathrm{C}_{2} \mathrm{H}_{4} \mathrm{NaO}_{2} .3 \mathrm{H}_{2} \mathrm{O}, 3.0 \mathrm{~g} / \mathrm{L} \mathrm{NaHCO}$, and $7.5 \mathrm{ml}$ salt solution. (The composition of the salt solution, per liter: $1.0 \mathrm{~g} \mathrm{FeSO}_{4} .7 \mathrm{H}_{2} \mathrm{O}, 20.0 \mathrm{~g} \mathrm{MgSO}_{4} .7 \mathrm{H}_{2} \mathrm{O}, 1.0 \mathrm{~g}$ $\mathrm{MnSO}_{4} .4 \mathrm{H}_{2} \mathrm{O}, 5.0 \mathrm{~g} \mathrm{CaCl} 2.2 \mathrm{H}_{2} \mathrm{O}, 46.0 \mathrm{~g} \mathrm{Na}_{2}$ EDTA. $\left.2 \mathrm{H}_{2} \mathrm{O}\right)$. The $\mathrm{pH}$ was adjusted to $6.8-6.9$ by adding $3.0 \mathrm{~N} \mathrm{NaOH}$ solution. $47 \mathrm{ml}$ of medium was dispensed in $250 \mathrm{ml}$ conical flask and sterilized at $121^{\circ} \mathrm{C}$ for 20 minutes. After sterilization, $3.0 \mathrm{ml}$ of dextrose solution [50 \% (w/v) prepared and sterilized separately] and $2.0 \mathrm{ml}$ of calcium carbonate solution [25 \% (w/v) prepared and separately sterilized] was added. Modification of the medium used by Vazquez et al., (2009) was used. In P10 medium concentration of potassium dihydrogen phosphate is higher. In earlier reported medium of Vazquez et al ,the potassium dihydrogen phosphate is $2 \mathrm{~g} / \mathrm{L}$ whereas in P10 medium it is $10 \mathrm{~g} / \mathrm{L}$. Sodium acetate, sodium bicarbonate and salt solution (S1) is also additional in P10 medium which is not there in medium reported by Vazquez et al.,(2009). The P10 medium was also used as a seed medium. Conditions for shake flask fermentation: One $\mathrm{ml}$ of Streptococcus equi subsp. zooepidemicus ATCC 39920 frozen glycerol stock was transferred to $50 \mathrm{ml}$ vegetative medium in $250 \mathrm{ml}$ Erlenmeyer flasks. The flask was incubated at $37{ }^{\circ} \mathrm{C} \pm 1$ and $90 \mathrm{rpm}$ at $5 \mathrm{~cm}$ displacement for 7 to $12 \mathrm{~h}$ (Scigenics shaker). When the $\mathrm{pH}$ of the seed reached between 6.3 to 6.4 and optical density at $600 \mathrm{~nm}$ reached 2.0 in P10 medium (after OD 1.0 the broth was suitably diluted and then multiplied by dilution factor), $1.5 \mathrm{ml}$ of the inoculum was transferred to the $50 \mathrm{ml}$ fermentation medium. The inoculated fermentation shake flasks were incubated at $37^{\circ} \mathrm{C}$ at 90 rpm. After 24 hours the flasks were harvested and analyzed for $\mathrm{pH}, \mathrm{OD}$ and yield of HA. Experiments for HA production were done in batch mode.

Standard dextrose addition in P10 medium: $3 \mathrm{ml}$ of 50\% dextrose added in $50 \mathrm{ml} \mathrm{P10} \mathrm{medium.} \mathrm{For} \mathrm{experiments}$ on combination of dextrose and fructose additions has been done in (1) $50 \%$ fructose $+50 \%$ dextrose: $1.5 \mathrm{ml}$ of
$50 \%$ fructose $+1.5 \mathrm{ml}$ of $50 \%$ dextrose, (2) $70 \%$ fructose + $30 \%$ dextrose: $3.5 \mathrm{ml}$ of $50 \%$ fructose $+1.5 \mathrm{ml}$ of $50 \%$ dextrose

\section{Analytical Methods}

Cell mass (biomass) measurement is required to determine the extent of growth. To determine the growth of the culture the optical density of culture was measured at $600 \mathrm{~nm}\left(\mathrm{~A}_{600}\right)$ using medium as a blank by a spectrophotometer (Shimadzu, UV120-02, Japan).

\section{Analysis of $H A$}

In the measurement of HA concentration, the fermented broth sample was first diluted with water (one volume) and centrifuged at $3000 \mathrm{rpm}$ for 5 minutes to remove solid mass. The resulted supernatant solution was then subjected to HA precipitation by mixing with two volumes of ethanol. The precipitate was collected by centrifugation at $3000 \mathrm{rpm}$ for 20 minutes and the precipitate was redissolved in water.To this was then added disodium tetraborate solution and boiled for 10 minutes.After cooling to room temperature ,carbazole solution was added and heated in water bath for 15 minutes and read at $525 \mathrm{~nm}$ with D-glucuronic acid as the standard (Bitter and Muir, 1962).

\section{Nutrient Concentration Analysis}

Total sugar was measured using Anthrone's reagent method (Trevelyan and Harrison, 1952).

\section{Effect of Various Components (Metabolites and Precursors) on HA Production}

Carbon sources used in shake flask level were dextrose, lactose, maltodextrine and dextrine. $3.0 \mathrm{ml}$ of $50 \%(\mathrm{w} / \mathrm{v})$ solution of each sugar was added as mentioned earlier. To study the effect of nitrogen source, soya peptone (15 $\mathrm{g} / \mathrm{L})$, neo peptone $(15 \mathrm{~g} / \mathrm{L})$, meat extract $(5 \mathrm{~g} / \mathrm{L})$, yeast autolysate (2.5 and $5.0 \mathrm{~g} / \mathrm{L})$, purified casein (15 and 20 $\mathrm{g} / \mathrm{L})$ were added in P10 shake flask fermentative medium. The shake flask fermentation was carried out as mentioned earlier.

Tween 80 was added at $0.1 \%$ and $0.05 \%$ to the P10 medium to study the effect on HA production.

Vitamin solution comprising riboflavin $1.0 \mathrm{~g} / \mathrm{L}$, pyridoxine $\mathrm{HCl} 1.72 \mathrm{~g} / \mathrm{L}$, thymine $\mathrm{HCl} 0.001 \mathrm{~g} / \mathrm{L}$, folic 
acid $0.52 \mathrm{~g} / \mathrm{L}$, nicotinamide $0.11 \mathrm{~g} / \mathrm{L}$, pantothenic acid $0.2 \mathrm{~g} / \mathrm{L}$, biotin $0.36 \mathrm{~g} / \mathrm{L}$ and choline chloride $4.04 \mathrm{~g} / \mathrm{L}$ was added to the $50 \mathrm{ml}$ shake flask fermentative medium taken in $250 \mathrm{ml}$ conical flask in different volumes from $0.05 \mathrm{ml}, 0.1 \mathrm{ml}$ and $0.2 \mathrm{ml}$. This was then incubated on shaker after inoculation with $S$. equi subsp. zooepidemicus ATCC 39920. Pantothenic acid (8.33 mg/L) was supplemented to P10 medium to study the effect on yield of HA. Filter sterilized solutions of copper sulphate, manganese sulphate and zinc sulphate was added at concentration of $0.025 \%, 0.005 \%$ and $0.01 \%$ to the shake flask fermentative P10 medium and incubated on shaker. $\mathrm{MgSO}_{4}$ at concentration $0.2 \mathrm{~g} / \mathrm{L}, 0.6 \mathrm{~g} / \mathrm{L}, 0.8$ $\mathrm{g} / \mathrm{L}, 1.0 \mathrm{~g} / \mathrm{L}$ and $1.2 \mathrm{~g} / \mathrm{L}$ were added in P10 medium for the production of $\mathrm{HA}$. L-arginine $\mathrm{HCl}$ at $2.0 \mathrm{~g} / \mathrm{L}$ and tannic acid at $0.1 \mathrm{~g} / \mathrm{L}$ was added in P10 shake flask medium and incubated in the shaker. P10 medium was supplemented with $0.7 \mathrm{~g} / \mathrm{L}$ of uridine to study the effect on HA production. The experiments were conducted using P10 medium. Addition of components such as glutamine $(0.1$ to $3.0 \mathrm{~g} / \mathrm{L})$, arginine $(0.06$ to $3.0 \mathrm{~g} / \mathrm{L})$, tannic acid $(0.1 \mathrm{~g} / \mathrm{L})$, uridine $(0.75 \mathrm{~g} / \mathrm{L})$, active dry yeast (5 to $10 \mathrm{~g} / \mathrm{L})$, and sodium glucuronate $(0.25 \mathrm{~g} / \mathrm{L})$ were tested to see the effect on the production of HA. Larginine $\mathrm{HCl}(0.5$ to $3.0 \mathrm{~g} / \mathrm{L})$ and L-glutamine (0.5 to 3.0 $\mathrm{g} / \mathrm{L})$ were added together in P10 medium to see the effect on production of HA.

\section{RESULTS AND DISCUSSIONS}

\section{Colony Selection and Organism Storage}

For maximum production of good quality of HA, selection of appropriate colony is the most important factor. Highly mucoid colony was selected for studies on production of HA. The slimy layer surrounding bacterial colonies that can be attributed to HA synthesis. S. equi subsp. zooepidemicus ATCC 39920 was obtained from ATCC and subsequently studied for their stability of HA production characteristics upon maintenance and storage. The above culture was found to exhibit consistent growth and productivity for at least up to period of two months when maintained on glycerol stocks. Hence the cultures of S. equi subsp. zooepidemicus were routinely stored as glycerol stocks throughout the present study.

Effect of Environmental and Nutritional Conditions on HA Production under Shake Flask Conditions
Developing an appropriate fermentation strategy for HA production is necessary for an economical fermentation process. Fermentation process development involves the determination of culture conditions and the establishment of the cultivation mode. The influential factors in cultural conditions include medium composition, temperature, $\mathrm{pH}$, aeration and agitation. Several reports have been published with the culture conditions of HA production (Shu-Jen Chen et al., 2009).

For studies on production of HA under shake flask conditions, medium designated as P10 medium was used.. It was modified medium as reported by Vazquez et al., (2009). P10 medium contained dextrose and peptone as carbon and nitrogen sources respectively. Addition of dextrose in P10 medium was found optimum when used in HA production at shake flask level using S. equi subsp. zooepidemicus ATCC 39920, the yield of HA obtained was $0.70 \pm 0.03 \mathrm{~g} / \mathrm{L}$.

\section{Effect of Carbon Sources on HA Production}

Shibata et al., (1994) reported the production of HA in a medium containing glucose and fructose as a major carbon source to accumulate HA of high molecular weight in the culture mixture.

Various carbon sources such as dextrose, fructose, maltose, sucrose, malic acid, maltodextrin and lactose were studied. Dextrose was found to be more effective for the production of HA using P10 medium. There was no significant effect on production of HA when dextrose was replaced by combination of $50 \%$ fructose and $50 \%$ dextrose. There was no significant effect on HA production when dextrose was replaced by combination of $70 \%$ fructose and $30 \%$ dextrose. Addition of lactose also promoted the growth and HA productivity. Maltose did not give good productivity of HA. All experiments with P10 medium were carried out with dextrose as carbon source. Rangaswamy et al., (2008) used sucrose and lactose as the best carbon source that the organism could utilized for the production of HA. Zhang et al., (2006) used starch as the carbon source for the production of hyaluronate from $S$. zooepidemicus NJUST01. The medium with maltodextrin showed $30 \%$ higher HA productivity. There are no reports cited in use of maltodextrin as a carbon source to increase the yield of HA. Table 1 showed the effect of carbon sources 
on the production of HA. When P10 medium was used the yield of HA was $0.70 \pm 0.03 \mathrm{~g} / \mathrm{L}$.

Table 1. Effect of various carbon sources on production of HA by $S$. equi subsp. zooepidemicus ATCC 39920 using P10 medium.

\begin{tabular}{|lcc|}
\hline \multicolumn{2}{|c|}{ Carbon source used in fermentation medium } & Yield of HA (g/L) \\
\hline Dextrose & $30 \mathrm{~g} / \mathrm{L}$ & $0.70 \pm 0.3$ \\
$50 \%$ Fructose $+50 \%$ Dextrose & $0.46 \pm 0.02$ \\
$70 \%$ Fructose + 30\% Dextrose & $0.23 \pm 0.01$ \\
Sucrose & $30 \mathrm{~g} / \mathrm{L}$ & $0.51 \pm 0.02$ \\
Maltodextrin & $30 \mathrm{~g} / \mathrm{L}$ & $0.92 \pm 0.05$ \\
Lactose & $30 \mathrm{~g} / \mathrm{L}$ & $0.5 \pm 0.02$ \\
Dextrin & $30 \mathrm{~g} / \mathrm{L}$ & $0.55 \pm 0.02$ \\
Maltose & $30 \mathrm{~g} / \mathrm{L}$ & $0.5 \pm 0.02$ \\
\hline
\end{tabular}

Table 2. Effect of various nitrogen sources on production of HA using $S$. equi subsp. zooepidemicus ATCC 39920

\begin{tabular}{|lll|}
\hline $\begin{array}{l}\text { Nitrogen sources used in } \\
\text { fermentation medium }\end{array}$ & $\begin{array}{l}\text { Concentration } \\
(\mathrm{g} / \mathrm{L})\end{array}$ & $\begin{array}{l}\text { Yield of HA } \\
(\mathrm{g} / \mathrm{L})\end{array}$ \\
\hline Soya Peptone & 15.0 & $0.54 \pm 0.02$ \\
Biopeptone & 15.0 & $0.65 \pm 0.03$ \\
Neo Peptone & 20.0 & $0.62 \pm 0.03$ \\
Meat Extract & 15.0 & $0.68 \pm 0.03$ \\
Brain Heart Infusion Broth & 5.0 & $0.60 \pm 0.02$ \\
& 5.0 & $0.63 \pm 0.03$ \\
Yeast Autolysate & 2.5 & $0.50 \pm 0.02$ \\
& 5.0 & $0.49 \pm 0.01$ \\
& 10.0 & $0.29 \pm 0.02$ \\
Purified Casein & 15.0 & $0.23 \pm 0.01$ \\
& 20.0 & $0.31 \pm 0.02$ \\
\hline
\end{tabular}

\section{Effect of Various Nitrogen Sources}

The production of HA requires optimal amount of carbon and nitrogen sources and $\mathrm{C} / \mathrm{N}$ ratio should be predicted for maximal production (Armstrong et al., 1997). In case of P10 medium, when meat peptone was replaced by soya peptone, no significant effect was observed. When meat peptone was replaced by biopeptone and neopeptone no significant increase was observed. When meat extract, yeast autolysate and brain heart infusion broth was added at $5.0 \mathrm{~g} / \mathrm{L}$ respectively in P10 medium, the HA production did not increase. Addition of casein was not found effective. It has been reported earlier that the organism was unable to utilize casein efficiently (Armstrong et al., 1997). Table 2 shows the effect of nitrogen source on the production of HA.

\section{Effect of Tween 80}

When P10 medium was used the yield of HA was 0.7 $\pm 0.03 \mathrm{~g} / \mathrm{L}$. The medium $(50 \mathrm{ml})$ in $250 \mathrm{ml}$ Erlenmeyer flask, after inoculating with $S$. equi subsp. zooepidemicus ATCC $39920\left(\mathrm{~A}_{600}=2.0, \mathrm{pH} 6.3\right.$ and 3\% level $)$ was incubated at $37{ }^{\circ} \mathrm{C} \pm 1$ on an orbital shaker $(90 \mathrm{rpm})$ for 24 h. The yield of HA was low when tween 80 was added at $0.1 \%$ and $0.05 \%$ to the P10 medium (Table 3 ). Like all other bacteriolytic enzymes, Tween 80 acts as a surfactant which depletes the cellular wall of the organisms there by inducing the organism to strengthen its cell wall by building up the capsular surrounding strong by producing more HA. In this case addition of tween 80 does not resulted in significant production and it repressed the synthesis of HA when used in higher concentration such as $0.1 \%$ and $0.05 \%$. Morita et al. (1993) achieved $4.1 \mathrm{~g} / \mathrm{L}$ HA by using tween 80 in a medium with glucose and yeast extract which yielded $0.93 \mathrm{~g} / \mathrm{L}$ HA without tween 80 .

Table 3. Effect of Tween 80 on HA production when S. equi subsp. zooepidemicus ATCC 39920 was used

\begin{tabular}{|ll|}
\hline Tween $80 \%$ & Yield of HA $(\mathrm{g} / \mathrm{L})$ \\
\hline 0.05 & $0.5 \pm 0.02$ \\
0.1 & $0.4 \pm 0.02$ \\
$0 \%$ & $0.7 \pm 0.03$ \\
\hline
\end{tabular}

\section{Effect of Vitamin Solusions}

Bracke and Thacker (1985) used vitamins in the medium to grow the culture of streptococci for production of HA. Effect of vitamin solution was studied on the basis of study conducted by Akaska et al., (1989). Addition of pantothenic acid at a concentration of $8.33 \mathrm{mg} / \mathrm{L}$ gave good yield with P10 medium which was found to be optimum. Lesser concentration of the pantothenic acid (2.083 $\mathrm{mg} / \mathrm{L}$ and $4.167 \mathrm{mg} / \mathrm{L})$ did not result in increase in yield (Table 4 ). 
Table 4. Effect of pantothenic acid supplementation on production of HA

\begin{tabular}{|lll|}
\hline Carbon source used in & Concentration & Yield of HA \\
fermentation medium & $(\mathrm{mg} / \mathrm{L})$ & $(\mathrm{g} / \mathrm{L})$ \\
\hline & 2.083 & $0.75 \pm 0.03$ \\
Pantothenic Acid & 4.167 & $0.78 \pm 0.03$ \\
& 8.33 & $0.87 \pm 0.04$ \\
\hline
\end{tabular}

Vitamin solution comprising riboflavin $1.0 \mathrm{~g} / \mathrm{L}$; pyridoxine $\mathrm{HCl} 1.72 \mathrm{~g} / \mathrm{L}$; thymine $\mathrm{HCl} 0.001 \mathrm{~g} / \mathrm{L}$; folic Acid $0.52 \mathrm{~g} / \mathrm{L}$; nicotinamide $0.11 \mathrm{~g} / \mathrm{L}$; pantothenic Acid $0.2 \mathrm{~g} / \mathrm{L}$; biotin $0.36 \mathrm{~g} / \mathrm{L}$ and choline chloride $4.04 \mathrm{~g} / \mathrm{L}$ was added to the $50 \mathrm{ml}$ shake flask medium taken in 250 $\mathrm{ml}$ conical flasks in different volumes from $0.05 \mathrm{ml}, 0.1$ $\mathrm{ml}$ and $0.2 \mathrm{ml}$. Addition of pantothenic acid at a concentration of $8.33 \mathrm{mg} / \mathrm{L}$ has influenced the production of HA and the usage of vitamin solution did not yield any improvement in the production of HA. Pantothenic acid is a precursor of Coenzyme A and helpful in aerobic metabolism which helps in the formation of acetyl CoA. Acetyl CoA is directly involved in the pathway by forming $\mathrm{N}$-acetylglucosamine from glucosamine 6 phosphate. The acetyl group is donated to the carbon ring by acetyl $\mathrm{CoA}$ in the formation of $\mathrm{N}$ acetylglucosamine which is an important precursor in the formation of HA (Chong et al., 2005).

When P10 medium was used the yield of HA was 0.7 $\mathrm{g} / \mathrm{L}$. The medium $(50 \mathrm{ml})$ in $250 \mathrm{ml}$ Erlenmeyer flask, after inoculating with $S$. equi subsp. zooepidemicus ATCC 39920 ( $\mathrm{A}_{600} 2.0, \mathrm{pH} 6.3$ and 3\% level) was incubated at $37^{\circ} \mathrm{C} \pm 1$ on an orbital shaker $(90 \mathrm{rpm})$ for $24 \mathrm{~h}$. Pantothenic acid at concentration of $8.33 \mathrm{mg} / \mathrm{L}$ supplemented to the P10 medium gave yield of $0.87 \mathrm{~g} / \mathrm{L}$ from $0.70 \mathrm{~g} / \mathrm{L}$. When $1.0 \mathrm{ml}$ solution of vitamin mixture containing riboflavin $1.0 \mathrm{~g} / \mathrm{L}$, pyridoxine $\mathrm{HCl} 1.72 \mathrm{~g} / \mathrm{L}$, thymine $\mathrm{HCl} 0.001 \mathrm{~g} / \mathrm{L}$, folic acid $0.52 \mathrm{~g} / \mathrm{L}$, nicotinamide $0.11 \mathrm{~g} / \mathrm{L}$, pantothenic acid $0.2 \mathrm{~g} / \mathrm{L}$, biotin $0.36 \mathrm{~g} / \mathrm{L}$ and choline chloride $4.04 \mathrm{~g} / \mathrm{L}$ was added into the P10 medium, an HA yield of $0.65 \pm 0.03 \mathrm{~g} / \mathrm{L}$ was obtained.

\section{Effect of Metal lons}

Effect of various metal ions such as ferrous, copper, zinc and manganese with P10 medium on the production of HA was studied. The addition of copper sulphate, manganese sulphate and zinc sulphate at a concentration of $0.025 \%, 0.005 \%$ and $0.01 \%$ does not show any increase in the HA production. $10 \mathrm{mg} / \mathrm{L}, 20 \mathrm{mg} / \mathrm{L}$ and $30 \mathrm{mg} / \mathrm{L}$ of ferrous sulphate addition to the P10 medium was studied for the production of HA and found insignificant. Magnesium sulphate at different concentrations around $0.2 \mathrm{~g} / \mathrm{L}, 0.6 \mathrm{~g} / \mathrm{L}, 0.8 \mathrm{~g} / \mathrm{L}, 1.0 \mathrm{~g} / \mathrm{L}$ and $1.2 \mathrm{~g} / \mathrm{L}$ was studied and $1.0 \mathrm{~g} / \mathrm{L}$ was found to be the optimum concentration for the production of HA in P10 medium. Importance of the addition of $\mathrm{MgSO}_{4}$ salt in the HA fermentation media was explained by Nimrod et al., (1988). According to them $\mathrm{MgSO}_{4}$ concentration should be maintained at a concentration greater than $0.05 \%$, which is the cofactor required for the HAS enzyme to become a holoenzyme. Yields in the nonaerated fermentors are from about 2 to about $3 \mathrm{~g} / \mathrm{L}$ of HA with an average molecular weight (MW) from about 1.5 to about $2 \times 10^{6} \mathrm{Da}$. Similarly, addition of ferrous ions inhibits the production of hemolysin and certain endotoxins (Poli et al., 1996) which affects the properties of the finished product. Rangaswamy et al. (2008) showed that addition of these metal ions increase the molecular weight of the HA formed. In shake flask studies conducted none of these ions except magnesium sulphate was found to have positive effect over the production of high molecular weight HA. Increased in the phosphate concentration in the fermentation media increases the molecular weight of the HA molecule without increasing the yield of HA (Stahl et al., 2003) and always there exists an inverse relation between the molecular weight and yield of HA.

Addition of different metals in the fermentation process of $\mathrm{HA}$ is known to enhance capsule production in various bacteria. The effect of $\mathrm{CuSO}_{4}, \mathrm{MnSO}_{4}$ and $\mathrm{ZnSO}_{4}$ at $0.025 \%$ (final concentration) was tested on the yield of $\mathrm{HA}$ at the end of $24 \mathrm{~h}$ of fermentation. While there was no significant difference between the control (no metal addition) and the flasks treated with $\mathrm{CuSO}_{4}$ or $\mathrm{MnSO}_{4}$, a significant portion $(60 \%)$ of total $\mathrm{HA}$ in the medium treated with $\mathrm{ZnSO}_{4}$ was found to be in the higher molecular weight region (greater than $800 \mathrm{KDa}$ ) (Rangaswamy et al., 2008).

\section{Effect of L-Arginine $\mathrm{HCl}$ Supplementation}


The yield of HA in P10 medium without addition of Larginine was $0.7 \pm 0.03 \mathrm{~g} / \mathrm{L}$. Table 5 shows the effect of Larginine on yield of HA.

Table 5. Effect of supplementation of $\mathrm{L}$-arginine $\mathrm{HCl}$ in $\mathrm{P} 10$ medium
\begin{tabular}{|ll|}
\hline Concentration of $\mathrm{L}$-arginine $(\mathrm{g} / \mathrm{L})$ & Yield of $\mathrm{HA}(\mathrm{g} / \mathrm{L})$ \\
\hline 0.06 & $0.64 \pm 0.03$ \\
0.12 & $0.65 \pm 0.03$ \\
0.50 & $0.68 \pm 0.03$ \\
2.0 & $0.85 \pm 0.04$ \\
3.0 & $0.82 \pm 0.04$ \\
\hline
\end{tabular}

There was significant increase in the yield of HA when L-arginine at $2.0 \mathrm{~g} / \mathrm{L}$ was added in P10 medium under shake flask conditions by $S$. equi subsp. zooepidemicus ATCC 39920.There are no reports cited in use of Larginine $\mathrm{HCl}$ in $\mathrm{HA}$ production by $S$. equi subsp. zooepidemicus ATCC 39920. Gao et al., (2006) used arginine at a concentration of $2.0 \mathrm{~g} / \mathrm{L}$ to produce HA from nutrient rich medium using Streptococcus zooepidemicus H23. Armstrong et al., (1997) reported the essential amino acids that are necessary for the growth and production of HA from Streptococcus zooepidemicus ATCC 35246 which includes L-arginine hydrochloride. Role of arginine is that it acts as a carbon and nitrogen donor in the purine and pyrimidine synthesis, and the microbes follow a complex energy consuming pathway for the synthesis of the amino acid L-arginine. Supplying this amino acid in the media could save the energy consumption in the organism.

\section{Effect of L-Glutamine Supplementation}

The yield of HA in P10 medium without added glutamine was $0.7 \pm 0.03 \mathrm{~g} / \mathrm{L}$. Effect of glutamine at different concentrations was studied. There was significant increased in HA production observed at 2.0 $\mathrm{g} / \mathrm{L}$ concentration of glutamine in P10 medium as shown in Table 6. Glutamine is a component that involves directly in the pathway for HA synthesis and donates the amine group to the conversion of fructose 6 phosphate in to glycosoamine 6 phosphate which is an important precursor for HA synthesis that produces $\mathrm{N}$ acetylglucosamine in further reactions (Chong et al., 2005). $2.0 \mathrm{~g} / \mathrm{L}$ of glutamine yields maximum amount of HA.

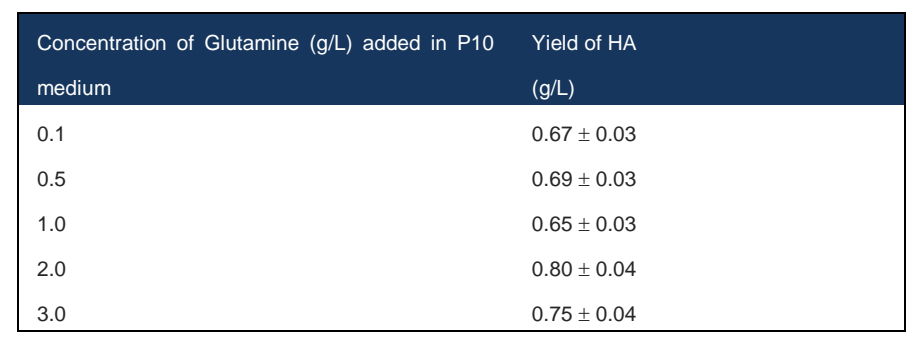

\section{Synergystic Effect of L-Arginine $\mathrm{HCl}$ and L- Glutamine}

The yield of HA in P10 medium was $0.7 \pm 0.03 \mathrm{~g} / \mathrm{L}$. Combined effect of L-arginine and L-glutamine was studied at different concentrations. There was significant increased in production of HA observed at $2.0 \mathrm{~g} / \mathrm{L}$ each in P10 medium as shown in Table 7.

Table 7. Combined effect of supplementation of $\mathrm{L}$-arginine $\mathrm{HCl}$ and $\mathrm{L}$-glutamine on production of $\mathrm{HA}$.

\begin{tabular}{|lll|}
\hline Concentration of L-arginine $\mathrm{HCl}$ & $\begin{array}{l}\text { Concentration of } \mathrm{L}- \\
(\mathrm{g} / \mathrm{L})\end{array}$ & $\begin{array}{l}\text { Yield of } \mathrm{HA} \\
\text { glutamine }(\mathrm{g} / \mathrm{L})\end{array}$ \\
\hline 0.5 & 0.5 & $(\mathrm{~g} / \mathrm{L})$ \\
1.0 & 1.0 & 0.75 \\
2.0 & 2.0 & 0.85 \\
3.0 & 3.0 & 1.0 \\
\hline
\end{tabular}

\section{Effect of Tannic Acid}

Tannic acid at $0.1 \mathrm{~g} / \mathrm{L}$ concentration was used at shake flask level to study the effect on HA production. There was no significant effect of tannic acid on HA production in P10 medium. In case of P10 medium without added tannic acid the HA yield was $0.7 \pm 0.03$ $\mathrm{g} / \mathrm{L}$ whereas, after addition of tannic acid the yield of HA was found to be $0.68 \pm 0.03 \mathrm{~g} / \mathrm{L}$. Tannic acid is hydroxyl compound that have the ability to repress the synthesis of hyaluronidase enzyme which degraded HA (Miyamori et al., 1989). So addition of tannic acid to the fermentation media, represses the less amount of hyaluronidase from synthesis and prevents the degradation of the HA chains formed in the cell wall. Use of tannic acid at a very low concentration at about $0.1 \mathrm{~g} / \mathrm{L}$ increased the viscosity of the broth shown that the increase in molecular weight of HA but decrease in the HA production.

\section{Effect of Uridine}

Table 6. Effect of supplementation of glutamine on production of $\mathrm{HA}$ 
Uridine at a concentration of $0.75 \mathrm{~g} / \mathrm{L}$ with P10 medium gave good productivity. The yield of HA was increased from $0.7 \pm 0.03 \mathrm{~g} / \mathrm{L}$ to $1.045 \pm 0.04 \mathrm{~g} / \mathrm{L}$. Addition of uridine to the fermentation medium considerably increased the production of $\mathrm{HA}$ at a concentration of $0.75 \mathrm{~g} / \mathrm{L}$, which might be due to the involvement of the uridine molecules in the synthetic pathway of HA.These molecules are not synthesized by the organism and it is obtained from the external sources (Park et al., 1996).

\section{Effect of Uracil}

Liu et al. (2009) reported the influence of nucleotide bases on microbial HA production using fractional factorial design, uracil to be most significant factor for cell growth and HA production. In P10 medium, when uracil was added at $0.1 \mathrm{~g} / \mathrm{L}$, the yield of $\mathrm{HA}$ was increased from $0.70 \pm 0.03 \mathrm{~g} / \mathrm{L}$ (without uracil) to 0.77 $\pm 0.035 \mathrm{~g} / \mathrm{L}$ (with supplementation of uracil).

Uracil which is a nitrogenous base in the nucleotide of RNA molecule is not synthesized by the organism Streptococcus species. Poli et al. (1996) experimented with uracil and studied the effect of uracil on the HA production. Uracil is involved in the uridine synthesis which is involved directly in the biosynthetic pathway of HA. Hence addition of uracil at an optimum concentration of $0.1 \mathrm{~g} / \mathrm{L}$ could increase the production of HA. Uracil, acting as a precursor of UDP-glucose, served as an activator on the production of $\mathrm{HA}$ by $S$. zooepidemicus. The optimal uracil addition could accelerate the synthesis of UDP-glucuronic acid and UDP-N-acetylglucosamine, which are the precursors for HA synthesis, and thus improved the HA productivity.

\section{Effect of L-Arginine $\mathrm{HCl}$ and Tannic Acid}

When L-arginine hydrochloride at $2.0 \mathrm{~g} / \mathrm{L}$ and tannic acid at $0.1 \mathrm{~g} / \mathrm{L}$ were added in P10 medium, the yield of $\mathrm{HA}$ was increased from $0.7 \mathrm{~g} / \mathrm{L}$ (without supplementation of L-arginine and tannic acid) to 1.029 $\mathrm{g} / \mathrm{L}$. L-arginine hydrochloride is the carbon and nitrogen donor for the synthesis of nucleotides the purines and pyrimidines which are the basic needs for the growth and multiplication. Production of arginine by the organism is also an energy consuming process and probably the organism Streptococcus species do not have the ability to synthesize all these amino acids as the tri carboxylic acid cycle is absent in them.Individually the effect was not as profound as when L-arginine and tannic acid were added together in the medium.There was more than $30 \%$ increase in yield of HA.

\section{Effect of Active Dry Yeast (ADY)}

When P10 medium was used the yield of HA was $0.7 \pm 0.03 \mathrm{~g} / \mathrm{L}$. Addition of active dry yeast at a concentration of $5.0 \mathrm{~g} / \mathrm{L}$ shown good HA productivity with P10 medium (Table 8).The yield of HA was increased from $0.7 \mathrm{~g} / \mathrm{L}$ to $0.85 \mathrm{~g} / \mathrm{L}$. Active dry yeast acts as a source of the nucleotides and amino acids which helps in the increase of productivity. Active dried yeast has $40 \%$ RNA. RNA is useful in pyrimidine biosynthesis and acts as a source of uridine. Addition of uridine which is involved in the synthesis of HA metabolic pathway, increases directly the production. Uridine active dried yeast was added at $5.0 \mathrm{~g} / \mathrm{L}$ concentration which was found to be optimal for the process.

Table 8. Effect of active dry yeast on HA production

\begin{tabular}{|lll|}
\hline Medium & Active dried yeast $(\mathrm{g} / \mathrm{L})$ & Yield of HA $(\mathrm{g} / \mathrm{L})$ \\
\hline & 5.0 & $0.85 \pm 0.04$ \\
P10 & 7.5 & $0.8 \pm 0.04$ \\
& 10.0 & $0.75 \pm 0.05$ \\
\hline
\end{tabular}

\section{Effect of Sodium Glucuronate}

Glucuronic acid $(0.25 \mathrm{~g} / \mathrm{L})$ was added in the P10 medium at initially or at $\log 8$. Addition of sodium glucuronate at $\log 8$ gave better HA production than added initially. When sodium glucuronate was added at $\log 8$ increased in HA yield from $0.7 \mathrm{~g} / \mathrm{L}$ to $0.85 \mathrm{~g} / \mathrm{L}$ in P10 medium was observed. When added initially the yield was marginally increased from $0.7 \mathrm{~g} / \mathrm{L}$ to $0.75 \mathrm{~g} / \mathrm{L}$. Sodium glucuronate is a metabolite that involves directly in the biosynthetic pathway of HA and the UDPglucuronic acid is directly incorporated in to the structure of HA. Hence, the supplementation of sodium glucuronate to the fermentation medium at a particular time activates the synthesis of $\mathrm{HA}$ and in the lengthening of molecular chain of HA. 


\section{CONCLUSION}

Various carbon and nitrogen sources were studied at shake flask conditions where glucose and peptone were found to be better. The addition of $\mathrm{MgSO}_{4} \cdot 7 \mathrm{H}_{2} \mathrm{O}$ at 1.0 $\mathrm{g} / \mathrm{L}$ and pantothenic acid improved the production of HA. Other metal ions like $\mathrm{MnSO}_{4}, \mathrm{FeSO}_{4}$, copper, zinc have no significant effect on HA production. The use of nutritional supplements like sodium glucuronate, maltodextrin, active dry yeast, uridine, L-arginine $\mathrm{HCl}$, L-glutamine and combination of L-arginine $\mathrm{HCl}$ and Lglutamine found to increased the yield of HA under shake flask conditions. There are no reports cited in use of sodium glucuronate, maltodextrin, active dry yeast and combination of L-arginine $\mathrm{HCl}$ and L-glutamine in microbial HA production. There are no reports cited in use of uridine, L-arginine $\mathrm{HCl}$ and L-glutamine in production of HA by S. equi subsp. zooepidemicus ATCC 39920 however there are reports in use of uridine, Larginine $\mathrm{HCl}$ and L-glutamine by other strains of Streptococcus zooepidemicus.

\section{REFERENCES}

Akaska H, Komasaki H, Avali T (1989) Fermentation method for producing hyaluronic acid. U. S. Patent No. 4,801,539.

Armstrong DC, Johns M R (1997) Culture conditions affect the molecular weight properties of hyaluronic acid produced by Streptococcus zooepidemicus. Applied Microbiology and Biotechnology 63: 2759-2764.

Bitter T, H M Muir (1962) A modified uronic acid carbazole reaction. Analytical Biochemistry 4: 330-333

Bracke J W, Kipling T (1985) Hyaluronic acid from bacterial culture. U. S. Patent No. 4,517,295.

Chen S J, Chen J L, Huang W C, Chen H L (2009) Fermentation process development for hyaluronic acid production by Streptococcus zooepidemicus ATCC 39920. Korean Journal Chemical Engineering 26: $428-432$

Chong B F, Blank L M, Mclaughlin R, Nielsen L K (2005) Microbial HA production. Applied Microbiology and Biotechnology 66: 341-351.

Duan Jie, X Yang, Li Zhang, Xu, Tan W S (2008) Effect of oxygen and shear stress on molecular weight of hyaluronic acid produced by Streptococcus zooepidemicus. Journal of Microbiology and Biotechnology 18: 718-724
Goa KL , Benfield P (1994) Hyaluronic acid a review of its pharmacology and use as a surgical aid in ophthalmology and its theoretical potential in joint disease and wound healing. Drugs 47:53666 .

Gao H J, Du G C, Chen J (2006) Analysis of metabolic fluxes for hyaluronic acid production by Streptococcus zooepidemicus. World Jounal of Microbiology and Biotechnology 22: 396-408.

Hasegawa S, Nagastsuru M, Shibutani, Yamamoto S, Hasebe S (1999) Productivity of concentrated hyaluronic acid using a maxblend fermenter. Journal of Bioscience Bioengineering 88: 68.

Kogan G, Soltes L, Stern R, Gemeiner P (2007) Hyaluronic acid: a natural biopolymer with a broad range of biomedical and industrial application. Biotechnology Letters 29: 17-25.

Kim SJ, Park SY, Kim CW (2006) A novel approach to the production of HA by Streptococcus zooepidemicus. Journal of Microbiology and Biotechnology 16: 1849-1855.

Kim J H, Yoo S J, Oh D K, Kweon Y G, Park D W, Lee C H, Gil G H (1996) Selection of a Streptococcus equi mutant and optimization of culture conditions for the production of high molecular weight HA . Enzyme and Microbial Technology 19: 440-445.

Liu L, Sun J, Zhang D, Du G, Chen J, Xu W (2009) Culture conditions optimization of HA production by Streptococcus zooepidemicus based on radial basis function neural network and quantum-behaved particle swarm optimization algorithm. Enzyme and Microbial Technology 44: 24-32.

Liu C, Sun Z, Du J, Wang J (2008) Response surface optimization of fermentation conditions for producing xylanase by Aspergillus niger SL05. Jounal of Industrial Microbiology and Biotechnology 35: 703-711.

Liu L, Sun J, Wenbo X, Guocheng D, Chen, J. (2009) Modeling and optimization of microbial HA production by Streptococcus zooepidemicus using radial basis function neural network coupling quantum-behaved particle swarm optimization algorithm. Biotechnology Progress 25: 1819 - 1825.

Miyamori T, Numazawa R, Sakimae A, Onishi H. (1989) Method of production of hyaluronic acid U. S. Patent No. 4,885,244.

Morita H, Fujii M (1991) Process for preparing hyaluronic acid. U. S. Patent No. 50,717,551.

Nimrod A, Greenman B, Kanner D, Landsberg M (1986) Method of producing high molecular weight sodium hyaluronate by fermentation of Streptococcus. US Patent No.4,780,414. 
Ogrodowski CS, Hokka CO, Santana MHA (2005) Production of Hyaluronic acid by Streptococcus. The effect of the addition of lysozyme and forced aeration in the formation and rheological properties of the product. Applied Biochemistry Biotechnology (121)753-761

Park JMG, Kang JD, Whan K (1996) Streptococcus zooepidemicus medium and process for preparing hyaluronic acid. US Patent No. 5496726.

Poli S, Bocchiola G, Casareto E, Leoni M, Mazni A, Ronzio E (1996) Process for preparation of hyaluronic acid by fermentation with Streptococcus. European Patent No. 0694616A2.

Rangaswamy V, Jain D (2008) An efficient process for production and purification of hyaluronic acid from Streptococcus equi subsp. zooepidemicus. Biotechnology Letters 30: 493-496.

Rangaswamy V, Jain D (2008) Optimisation of culture conditions for production and process of purification of high molecular weight hyaluronic acid. US Patent Application 20080138865.

Shibata Susumu, Kurato Yoshiyuki (1994) Production of HA. Japanese Patent No.06319579.

Trevelyan WE, Forrest RS, Harrison JS (1952) Determination of yeast carbohydrates with the anthrone reagent. Nature 170:626-627.

Trinder p (1969) Determination of blood glucose using an oxidase peroxidase system with a noncarcinogenic chromogen. Annual Clinical Biochemistry 6:24-30

Vazquez J A, Montemayor M I, Fraguas J, Murado M A (2009) High production of hyaluronic and lactic acids by Streptococcus zooepidemicus in fed-batch culture using commercial and marine peptones from fishing by-products Biochemical Engineering Journal 24:
125-130.

Zhang J, Ding X, Yang L, Kong Z (2006) A serum-free medium for colony growth and hyaluronic acid production by Streptococcus zooepidemicus NJUST01. Applied Microbiology and Biotechnology 72: 168-172.

\section{AUTHORS}

\section{Vinay J. Aroskar, MSc, PhD}

$\mathrm{He}$ is working in Industry since last 25 years. He has specialization in Microbial process development,strain improvement,Scale up based on chemical engineering software,Biotransformations and statistical media optimization.He has expertise in Patent Law.Having work in instrumentation he is also conversant in Regulatory, QA.and GMP audits. He is Technical Expert on Indian Pharmacopea commission and member of Advisory committee at Mitcon, Pune on Biotechnology and Pharmaceuticals. He is also familiar with Probiotics, Recombinant proteins, steroid transformations and secondary metabolites. He is working on Biopolymer HA since last 10 years.

\section{S.D. Kamat}

She is an Associate Professor and teaching Microbiology at undergraduate and graduate levels since last 30 years. She has worked on several projects funded by various agencies.

\section{D.V. Kamat, PhD}

$\mathrm{He}$ is the Head of Department of Microbiology and is the In - Charge of the Department of Biotechnology. He is the member of board of studies, Microbiology and Member of the Faculty of science in the University of Mumbai. His area of research is Environmental Sciences and Fermentation Technology.

\section{ULIS D-Senfe}

This journal is published by the University Library System of the University of Pittsburgh

as part of its D-Scribe Digital Publishing Program, and is cosponsored by the University of Pittsburgh Press. 